\title{
Established users and the making of telecare work in long term condition management: Implications for health policy
}

\author{
Anne Rogers ${ }^{\mathrm{a}, *}$, Sue Kirk ${ }^{\mathrm{b}}$, Claire Gately ${ }^{\mathrm{a}}$, Carl R. May ${ }^{\mathrm{c}}$, Tracy Finch ${ }^{\mathrm{d}}$

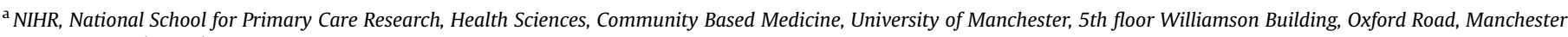 \\ M13 9PL, United Kingdom \\ ${ }^{\mathrm{b}}$ School of Nursing, University of Manchester, United Kingdom \\ ${ }^{\mathrm{c}}$ University of Southampton, United Kingdom \\ ${ }^{\mathrm{d}}$ Institute of Health and Society, University of Newcastle upon Tyne, United Kingdom
}

\section{A R T I C L E I N F O}

Article history:

Available online 15 February 2011

\section{Keywords:}

Patient's view

Telecare

Telehealthcare

Self-management

Primary care

Utilization

Policy

Longterm conditions

UK

\begin{abstract}
A B S T R A C T
Increasingly policy for long term condition management is focussing on new technologies. Telecare is viewed as a means of making services more responsive, equitable, cost and clinically-effective and able to play a central part in mediating between service users, professionals, and service providers. It has also been identified as helping to establish patient self-management for long term conditions. In this paper we consider the social practices of the work of telecare integration and incorporation for patients, their interactions with professionals and the synergy or otherwise with policy makers' expectations for how patients approach, use and interact with services. The research took place in England and in Wales and involved qualitative interviews with 31 individuals. Our research suggests that, telecare services provide both an adequate substitution for traditional services and additional benefits such as minimising the need to travel and the added reassurance of regular external surveillance. However, the nature of patient work involved is 'low level' rather than requiring higher level interpretation of readings and decision making commensurate with realising a policy vision of more independent and responsible self - managers. Indeed a paradox of the reliance and acceptance of telecare is the creation of new relationships and dependencies rather than the diminution of reliance envisaged by policy. The illumination of practices around telecare provides evidence for policy makers and others to adjust the predictions and presumptions about how telecare might enable and promote more effective long term condition management.
\end{abstract}

(c) 2011 Elsevier Ltd. All rights reserved.

\section{Introduction}

Since the early 1990s a key focus of health policy has been the deployment of self-care support and the modernization of services in pursuit of the effective management of long term conditions. Self-care usually refers to behaviour and actions taken by individuals towards their own health and illness: it comprises the actions to care for their long-term condition, and to prevent further illness deterioration. Within this agenda telecare is viewed as a means of making services more responsive, equitable, cost and clinically-effective, more highly co-ordinated and able to play a central part in mediating between service users, health, welfare professionals, and service providers (Department of

\footnotetext{
* Corresponding author. Tel.: +44 (0)161 275 7601; fax: +44 (0) 1612757600 .

E-mail addresses: anne.rogers@manchester.ac.uk (A. Rogers), sue.kirk@ manchester.ac.uk (S. Kirk), c.r.may@soton.ac.uk (C.R. May), Tracy.Finch@newcastle. ac.uk (T. Finch).
}

Health, 2005; Hudson, 2002). More specifically it has been identified as helping to establish patient self-management for long term conditions.

'Telecare' is defined as the use of information and communication technology to facilitate health and social care delivery to individuals in their own homes (Barlow, Bayer, \& Curry, 2006). Although it is accepted that terminology in this field is confusing, Barlow et al distinguish 'telecare' from other technology-mediated services as a those which bring care directly to the end-user, thus differentiating telecare from 'telemedicine', which is defined as the application of "ICT-based systems to facilitate the exchange of information between healthcare professionals - for example for diagnosis or referral-and which tends to focus on specific applications such as teledermatology or teleradiology" (Barlow et al., 2006, p.397).

In relation to telecare the balance of the management of care towards the home environment is seen as requiring an investment in 'upstream' interventions by providing enhanced primary and community care-based alternatives to secondary care and focussing 
on self-care and 'downstream' investment in measures to support self-care at the patient level (Department of Health, 2010). Evidence from systematic reviews shows that telecare systems can be used effectively to support 'down stream' self-care by people with chronic illnesses such as diabetes (Verhoeven et al., 2007), heart failure (Maric, Kaan, Ignaszewski, \& Lear, 2009), and chronic obstructive pulmonary disease (Jaana, Pare, \& Sicotte, 2009). Whilst, existing evidence tends to measure the degree of safety and focus on a pre-defined set of clinical outcomes as measures of success. This leaves a broader set of questions about the processes and conceptions of how telecare works in relation to the policy terms set for its success, the work and professional roles of professionals and the lives of patients. There is a need to account for the translation into practice of policy assumptions to see how telecare envisaged to work in principle does so in practice. This can be done through exploring whether and to what extent people are able integrate this into their everyday lives and use it for their own ends (Lehoux, Saint-Arnaud, \& Richard, 2004).

The notion of empowerment through fostering a sense of control and confidence forms the centre of aspirations for encouraging the self-management of long term conditions (Rogers, Bury, \& Kennedy, 2009). Empowered patients are viewed as undertaking more self-care activities independently of professionals and thus reducing demand on health services and professionals. As part of this hoped for change telecare systems hold out the promise of support for self-care in the form of accurate self-surveillance and monitoring that will lead to behavioural change through improvements in adherence to treatment regimens, and, through better management to lower utilisation of high cost services (e.g. admissions to hospital). In the latter respect both the use of telecare and self-care implicates a recursive relationship between formal service provision and the illness management which operates in the everyday life worlds of patients living with a long term condition (Gately, Rogers, \& Sanders, 2007).

It has also been suggested that the reaching out and expansion of technological practices to those with a chronic condition is likely to involve profound changes to traditional illness management including the reframing of monitoring activities and the modification of the power positions between those involved (May, Finch, Mair, \& Mort, 2005; Nicolini, 2007). In comparison to research on the operationalisation of clinical telemedicine services we know little about the processes of implementation adopted in the realm of telecare for patients and how the practices (i.e. "what is actually done') relate to the policy aspirations about outcomes for long term condition management (Obstfelder, Engeseth, \& Wynn, 2007).

\section{The patient work of integrating and accommodating telecare}

The ability to self-care in the policy literature has come to be associated with a set of desirable identities and attributes (e.g. the expert or activated patient). However, such ideal types of patienthood fail to acknowledge the role played by the social environments that individuals suffering from chronic illness inhabit and the activities from which illness identities are actually mobilized (Rogers et al., 2009). By contrast the notion of patient work refers to practices in everyday life and their expression in different patterns of social relationships. This is evident in the original work of Corbin and Strauss (1988) who identified three types of illness work undertaken by those with chronic illness: illness work (concerned with symptom management); everyday life work (concerned with the practical tasks such as housework, caring, and paid employment) and biographical work (concerned with the reconstruction of the ill person's biography). Thus, the utility of focussing on 'work' is that it can consider illness and its management as problems of action rather than identity.
The planned policy vision about chronic illness management and telecare implicates patients and health care professionals in a set of generated tasks which differ from those associated with the traditional health work division of labour. Professional labour involved in the management of chronic illness introduces new routinised ways of working which reduce work tasks to more simplistic components which are more easily downwardly delegated to others including to patients. Aspects of patients use of telehealth and telecare can be seen as professionally delegated work combined with existing skills previously learnt or used by the patient. As professional work becomes more protocol based, so too does the 'work' of patients. So for example in self-management tasks addressing communicating with the doctor and action planning are packaged together in a formulaic way which patients are now expected to undertake for themselves (Rogers et al., 2009).

With regard to telecare systems, patients, like professionals, manage to become competent users of specific tele-monitoring devices and become involved in diagnostic socio-technical work of home-care professional nurses and physicians (Oudshoorn, 2008). A review of technology and the work of patients with long term conditions illuminated how technology takes on the status of a personified 'other' around which a set of personal and relational attributions are constructed whilst permitting the extension of existing illness work in a way which incorporates new technologies. However, ambivalence about the value of technologies is evident in the potentially disruptive effects of health technologies on personal identities and strategies of managing whilst simultaneously providing new opportunities to complete aspects of illness work that were previously impossible (Gately, Rogers, Kirk, \& McNally, 2008). The everyday use of technology for long term condition management and its expression inpatterns of social relationships, social and material practices has been conceptualised as a product of people working collectively and individually to implement them (May et al., 2009). Thus the focus of this paper is on exploring the social practices and processes of the work of telecare integration and incorporation for patients and their interactions with professionals and the synergy or otherwise with professionals' and policy makers' expectations for how patients approach, use and interact with services.

\section{Methods}

As part of a wider programme of work (May et al., 2010) we undertook a study the aims of which were:

a) To illuminate how people experience, understand and negotiate the transfer of technologies into their homes.

b) To examine the extent to which telecare systems are incorporated into the life world of patients and carers and the factors that promote or inhibit integration.

Participants were recruited from four sites in England and one site in Wales that were using a range of technologies: telephone consultation/support for diabetes, remote monitoring of vital signs for Chronic Obstructive Pulmonary Disease (COPD) and heart disease and online consultations with GPs and Practice Nurses for Asthma (Table 1).

The sites were selected to enable variation to be included in the sample in terms of type of long-term condition, type of telecare system, length of time of existence of the telecare service, potential 'intrusiveness' of telecare and localities of different socio-economic and rural/urban status. At four sites all telecare users were invited to participate in the study and at one site (site A) users were purposefully sampled on the basis of age, gender and length of time they had been using the system. Thirty-one individuals took part in 
Table 1

Characteristics of the study sites.

\begin{tabular}{|c|c|c|}
\hline Study site & Long-term condition focus & Telecare system \\
\hline A & Diabetes & $\begin{array}{l}\text { Established system ( }>3 \text { years) integrated into mainstream health service provision. } \\
\text { Telephone consultation/support by trained support workers, supervised by diabetes specialist nurse. } \\
\text { Content of teleconsultation guided by computer-based protocol: blood glucose readings in previous } \\
7 \text { days reviewed and advice/support provided regarding management. Frequency of teleconsultations } \\
\text { determined by categorisation of glucose control based on individualised clinical assessment. Study } \\
\text { participants received monthly teleconsultations. }\end{array}$ \\
\hline B & Chronic obstructive pulmonary disease & $\begin{array}{l}\text { Pilot system ( }<6 \text { months) } \\
\text { Remote monitoring of vital signs. Patients take daily readings of weight; lung function; temperature; } \\
\text { blood oxygen; blood pressure and blood glucose using equipment supplied. These are transmitted } \\
\text { electronically to the district nursing team who compares readings with previously established } \\
\text { individualised parameters }\end{array}$ \\
\hline C & Chronic obstructive pulmonary disease & $\begin{array}{l}\text { Pilot system ( }<6 \text { months) } \\
\text { Remote monitoring of vital signs using a monitor attached to the telephone line. Patients expected to } \\
\text { provide daily readings at a set time of weight, blood oxygen, blood pressure and respond to questions } \\
\text { about their health. These readings are transmitted electronically to a call centre for review and comparison } \\
\text { with previously established individualised parameters and for any necessary action to be taken. }\end{array}$ \\
\hline $\mathrm{D}$ & Heart Disease & $\begin{array}{l}\text { Pilot system ( }<6 \text { months) being tested with a small number of patients. } \\
\text { Remote monitoring of vital signs Patients take daily readings of weight, lung function, blood oxygen; } \\
\text { blood pressure and blood glucose using equipment supplied. Readings transmitted electronically to } \\
\text { district nurse for review later that day to identify alerts' that might indicate the need for follow-up } \\
\text { call/visit by the district nursing team. }\end{array}$ \\
\hline $\mathrm{E}$ & Asthma & $\begin{array}{l}\text { Newly established service ( }<1 \text { year). } \\
\text { Online asthma consultation by GPs and Practice Nurses using a standardised questionnaire accessed through } \\
\text { practice website. Patients not expected to provide readings of any kind e.g. peak flow. Patients do not } \\
\text { necessarily receive any feedback from the practice nurse. Linked to this are email consultation with GPs, } \\
\text { online appointment system and access to own medical records. }\end{array}$ \\
\hline
\end{tabular}

the study of which 22 were patients and nine were their spouses/ carers. The majority of patients were male $(n=13)$ and over 65 years of age $(n=13)$. Eleven participants were living with chronic obstructive pulmonary disease (COPD), seven with diabetes, five with asthma and one with heart disease (Table 2). One person declined to participate and one died before the interview was conducted. The participants were all established users in so far as

Table 2

Participant Information.

\begin{tabular}{|c|c|c|c|c|c|}
\hline ID & Site & Participant type & Long-Term Condition & Sex & Age Grouping \\
\hline 1 & Site A & Patient & Diabetes & Male & $65-84$ years \\
\hline 2 & Site A & Patient & Diabetes & Male & $65-84$ years \\
\hline $3 a$ & Site A & Patient & Diabetes & Male & $65-84$ years \\
\hline $3 b$ & Site A & Spouse & $\mathrm{N} / \mathrm{A}$ & Female & $65-84$ years \\
\hline $4 a$ & Site A & Patient & Diabetes & Male & $65-84$ years \\
\hline $4 b$ & Site A & Spouse & $\mathrm{N} / \mathrm{A}$ & Female & $65-84$ years \\
\hline 6 & Site A & Patient & Diabetes & Male & 45-64 years \\
\hline 7 & Site A & Patient & Diabetes & Male & $45-64$ years \\
\hline 8 & Site A & Patient & Diabetes & Female & $45-64$ years \\
\hline $9 a$ & Site B & Patient & COPD & Male & $65-84$ years \\
\hline $9 b$ & Site B & Spouse & $\mathrm{N} / \mathrm{A}$ & Female & $65-84$ years \\
\hline 10 & Site B & Patient & COPD & Male & $45-64$ years \\
\hline $11 \mathrm{a}$ & Site B & Patient & COPD & Male & $65-84$ years \\
\hline $11 \mathrm{~b}$ & Site B & Spouse & $\mathrm{N} / \mathrm{A}$ & Female & $65-84$ years \\
\hline $12 \mathrm{a}$ & Site B & Patient & COPD & Female & $65-84$ years \\
\hline $12 b$ & Site B & Spouse & $\mathrm{N} / \mathrm{A}$ & Male & $65-84$ years \\
\hline $13 a$ & Site B & Patient & COPD & Male & $65-84$ years \\
\hline $13 b$ & Site B & Spouse & $\mathrm{N} / \mathrm{A}$ & Female & $65-84$ years \\
\hline 14 & Site B & Patient & COPD & Female & $65-84$ years \\
\hline 15 & Site C & Spouse & COPD & Female & Unknown \\
\hline 16 & Site C & Patient & COPD & Male & $65-84$ years \\
\hline 17 & Site C & Patient & COPD & Male & Unknown \\
\hline 19 & Site C & Patient & COPD & Female & $65-84$ years \\
\hline 20 & Site C & Spouse & COPD & Female & Unknown \\
\hline $21 a$ & Site D & Patient & Heart Disease & Male & $65-84$ years \\
\hline $21 b$ & Site D & Spouse & $\mathrm{N} / \mathrm{A}$ & Female & $65-84$ years \\
\hline 22 & Site E & Patient & Asthma & Female & $45-64$ years \\
\hline 24 & Site E & Patient & Asthma & Female & $25-44$ years \\
\hline 25 & Site E & Patient & Asthma & Female & $65-84$ years \\
\hline 26 & Site E & Patient & Asthma & Female & $25-44$ years \\
\hline 27 & Site E & Patient & Asthma & Female & $25-44$ years \\
\hline
\end{tabular}

the technology systems had been operating for sometime and that respondents who took part were selected on the basis that they had used the systems for two months or more.

At four sites nineteen semi-structured individual/joint interviews were conducted between October 2007 and February 2008. In seven of these interviews patients and their spouses/carers were interviewed together. Twelve individual interviews were conducted, ten with telecare users and two with spouses/carers due to the telecare user being too ill to participate. All interviews were conducted in the patient's home and lasted between one and two hours. During interviews there was the opportunity to observe participants using the devices and in most to view the equipment. Observational notes were taken about how patients/carers used the system and where the equipment was located in the home. In one site (Site E) a focus group was conducted with five users of an online asthma consultation service. The focus group aimed to gain an understanding of how participants used and experienced the telecare system but an additional aim was to test out and augment the findings emerging from the individual/joint interviews. The rationale for using a focus group was to use group dynamics as a means of facilitating individuals to compare their views and experiences.

A number of areas were explored in the individual/joint interviews and focus group. In order to contextualise their use of telecare participants were asked about their overall experience of living with their illness; its consequences for daily life; and their coping strategies and social support networks. In addition how they used services was explored as well as their relationships with professionals and other service providers. Participants were asked about the telecare system - its introduction, the purpose and perceived benefits of the device, ease of use and its impact and integration into everyday life. The interviews also explored whether there had been any changes to the way in which they managed their condition and whether they perceived changes in how they used services or the relationships they had with healthcare professionals as a result of using the telecare system. In the focus group interviews, emerging analytic themes in relation to user competency, legitimising demand and telecare-illness work integration were explored. All interviews were all audio-taped and fully transcribed. 
Team members read and reviewed the transcripts and identified key issues, concepts and themes. Meetings were held regularly throughout the interviewing, collation and analysis stages to discuss deviant cases and reach agreement around emerging themes. Themes that emerged from early interviews were used to inform the areas of investigation in later interviews. The findings below are structured around the final set of themes. The process of coding transcripts into chunks of data runs the risk of decontextualising the meaning of the data (Denscombe, 1998). Therefore, analyses of complete accounts were also conducted to enable further illumination of the emerging themes and retain an understanding of how an individual's experience of his or her current life world is determined by biographical experiences (Stamm et al., 2008). A case summary was produced for each participant and included a short description of the person interviewed and the central topics mentioned by the interviewee concerning the research questions (Flick, 1998). This summary enabled the contextual preservation of the key issues of importance for that particular individual.

A National Health Service Research Ethics Committee approved the study. Informed consent was obtained from all participants and careful attention paid to non-verbal signals indicating fatigue or disengagement during interviews. Participants were assured of anonymity, confidentiality and their right to withdraw from the study at any point.

\section{Results}

Three main themes emerged from the data in relation to use and acceptability of telecare: integrating and adapting telecare systems; impact of telecare on illness work; and mediating use and relationships with health services.

\section{Integrating and adapting to telecare systems}

At two sites telecare was delivered via familiar household objects - telephones and computers whereas at the other sites specialist equipment had been installed in the home. Most participants found the equipment easy to use at the basic level of turning the machine on and off and recording measurements (although at one site the equipment was perceived to be bulky and intrusive). Participants were on the whole prepared to 'put up' with or had at least got used to the equipment and had persevered long enough for incorporation into daily illness management to have occurred. There was a period of adjustment to newly introduced devices which included time to adjust to telecare's newness and intrusiveness. Any initial problems were described as having been resolved over time and few people continued to have technical problems.

How the telecare moved from the foreground to the background within a long-standing and familiar domestic environment suggested a process of accommodation. In some instances this occurred through conceptualising devices as everyday familiar household objects. For example in this quote the device is referred to as 'a clock radio'.

“Well it's visible [telecare device] as such, but it's at night that its dial is lit up because the, the day and the dates on there... and um, I think first of all my husband said, "Oh the light's flashing," well it doesn't flash but light there, but we don't take any notice of it now it's no different than say a clock radio."0.5(ID 20, spouse of patient with asthma)

Whilst patients were given basic instructions on how to use the equipment by a health care professional when the equipment was installed this was of minor utility in actually dealing with the experienced realities of the equipment in practice. Most participants reported not being forewarned about how telecare could impact on the home environment and in particular interfere with the operation of existing home technologies (e.g. TV, electric lights). Participants described how they had found ways of dealing with these problems themselves, which involved experiential learning (through trial and error) about how to use the device in the home.

“...I wasn't told when I was in [the sitting room] the television interfered with it...I had to find that out myself...It's too noisy." 0.5 (ID 10, COPD patient)

"No, odd times it blips...I call it blipping. Like when I put my finger in the probe for the blood oxygen, oxygen in the blood er, it will shoot up to ninety nine, it's never been ninety nine, now it, obviously I can tell that that's not going to work that, so what I do is take my finger out and do some of the others and I go back to that and try again so you know..."0.5(ID 12, COPD patient)

Notwithstanding the management of basic 'glitches' with equipment there was little room for the user to tailor the system in a way which best suited individual needs. Rather the equipment 'forced' the user into adapting to the workings of the machine. However, some participants were resourceful and found ways to 'subvert' the telecare system. Users of an asthma consultation service described how they had experienced problems in accessing the website and had consequently developed strategies for managing this in terms of using alternative access routes.

Some telecare systems imposed a new time frame on peoples' activities because of external instructions to perform vital sign monitoring at a set time everyday. None of the patients reported deviating from these externally imposed time frames. Nor did they appear to use the equipment for any additional self-testing if they felt unwell. Monitoring was perceived to be primarily the business of professionals and users approached telecare services with a traditional compliance rather than empowerment stance towards their own role.

"I sit there; I turn the radio off because there's got to be no talking or anything when it's on. I turn the radio off; tell him to shut up...And I sit over there and I wait. I go on over there about five to ten and they're on regularly at ten o'clock, so I don't keep them waiting or anything."0.5(ID 19, COPD patient)

Q: ...You know you mentioned you go in it for half hour and you sit down, do you do everything in the same order or do you, have you made changes?...

A: No, I do it in the same order every time...0.5(ID 12, COPD patient)

\section{The impact of telecare on existing illness work}

There were a number of dimensions and consequences of introducing of telecare. It introduced new time dimensions (discussed above) new tasks (e.g. monitoring) to patients' existing illness work and reconfigured the work done at the interface with health professionals.

Participants who were on the whole established telecare users had got used to the equipment and had persevered long enough for incorporation into daily illness management to have occurred. Before taking part in the telecare service most of the participants (there were a small number of exceptions) managed their condition following a traditional biomedical approach (e.g. medication and self-surveillance). Telecare necessitated a 'stepping up' of what people were already doing. For most the telecare system provided reassurance rather than making any significant change to or extension of patient initiated care. In this respect telecare was 
minimally disruptive in so far as it was a provision of service which did not apparently increase the burden of treatment for their users (May et al., 2009).

\section{“It doesn't interfere with us or anything, our life."0.5(ID 20, spouse of COPD patient) \\ "I don't test it at all until it comes to a week before we... unless I feel really bad and I think it, it must be me levels...So, with her ringing me, encourages me, really, to do it."0.5 (ID 8, diabetic patient) \\ "... Basically, I mean, what this system has done is emphasised and built on the previous knowledge I had, um, and has made me much more aware of my condition daily...And so it confirms okay, that I'm feeling better or I'm not feeling better having a good day or a bad day, um, but it gives you that feeling of security to know that somebody else is also looking..."0.5(ID 17, COPD patient)}

Although there were exceptions patients did not usually make independent decisions based on the readings or express the need to understand the meanings of the readings in relation to their own illness. In this respect there is little sense of the use of telecare creating empowered or activated patients. (The exceptions to this included a number of users of the diabetes telephone support service who appeared to have gained an increased awareness of their condition and as a result to have improved their selfmanagement in terms of increasing their blood sugar monitoring).

There was some variation between patients in understanding the readings from devices suggesting that a lack of perceived expertise, health literacy or interest may for some limit extending patient interpretation or action without the provision of more information or guidance.

"I mean, as I say, I can't read the spirometer and I can't read the blood pressure but the rest of the things, they're generally the same everyday...maybe a little bit of different but not a lot of difference. But the blood pressure and the spirometry I just don't understand".0.5(ID 9a, COPD patient)

A: I do a breath test, I blow into it, I haven't a clue what it's for.

B (Spouse of A): Well you do, you know what it's for.

A: I do, I know what it's for, because I do one every year when I go to the hospital and see the specialist but...

$\mathrm{B}$ : He doesn't understand whether the readings are good or bad.

A: ...that's right, whether they are good, bad, or indifferent.0.5(ID 13a, 13b COPD patient and spouse)

Nonetheless for others there was evidence that patients understood the meaning of results and were therefore quite capable of interpreting readings and in theory using them. It was simply that telecare use was not directly linked into engaging potential patient expertise to self- monitor and self-manage. This was particularly evident at one site where not only were participants unclear what the purpose of the telecare service was, when it was to be used or what happened to the information they provided but they described it as being irrelevant to their asthma selfmanagement. The information they were asked to provide was regarded as being too 'basic' and information they already possessed. However, information they perceived to be more relevant in managing their condition was overlooked.

"It is so basic, its stuff that actually is already known to your practice, they know if you smoke, they know what you do, you know it is fairly pointless .... It struck me that it wasn't actually a great deal of use um, because you need a peak flow reading and a comparison for that peak flow."0.5(ID 25, asthma patient)

"I think a day's worth of peak flows, you know a morning one a lunch one and a tea time one on an average day and you put that on it and then the next time you did a review you did it again, at least then they've got, they've had something to compare with .... it would also show for you, a seasonal picture, because you would get January, April, July, October and you can see seasonal discrepancies."0.5(ID 22, asthma patient)

It was assumed by participants that the technology was for the health care professional's benefit with indirect benefits flowing through the mediation of results conveyed to the professional. Thus, participants carried out additional illness work but this was orientated to the delegated 'dirty' work of professionals rather than empowering them to use the readings to directly benefit their own personal illness management.

A: So she set it all up and it all went clickety click, she showed us how to use it properly and she gave us the book and there's a chart inside that we fill in everyday and although we're not, um, our machine hasn't got a temperature, I've got my own thermometer and I also fill the column in for that as well.

Q: Right, right. So you, you, you um, you go through all the tests, so as well as the machine kind of storing information to be sent back through to the computer there, you also write it down, so you've got your own record of the reading?

A: That's right so if anybody did come in at anytime...it's all here with the notes on the top and they can look straight at that and compare it how the week has gone by, or even the month has gone by, they can see how it's differed.0.5(ID 15, spouse of COPD patient)

Some participants saw the telecare service as being for the general practice's benefit in terms of achieving targets.

"I have to say it strikes me as a tick the box target thing for the practice. I don't think it benefits the patient."0.5(ID 25, asthma patient)

"It's almost like we've ticked a box, oh we can do this now. Another string to our bow, sort of thing."0.5(ID 24, asthma patient)

Consequently there was an overall sense that patients were doing the work on behalf of health care professionals but without the power or responsibility to change their medications or take other actions. However, playing this role was constructed by participants as serving other purposes. The additional readings, recordings and the keeping of records provided a sense of achievement for patients in terms of meeting expectations of a 'compliant' patient role. It was a means of providing requested information in order to allow professionals to do their job properly whilst also increasing and promoting their own perceived legitimacy in the eyes of professionals due to their successful management of these new tasks.

Paradoxically perhaps given the lack of direct benefit to chronic illness work patients did not view telecare systems as an imposition. Many expressed gratitude for being given the opportunity to be involved in a new service because they had secured a sense of reassurance from being externally monitored. Whilst managing the telecare system involved the imposition of new time frames and additional regimes this was not problematised but rather embraced as a new focus in living. This may be because many users were elderly, housebound and socially isolated. Their involvement in the telecare service through taking readings provided them with a sense of purpose to daily life. A key benefit of the latter was engendering feelings of moral worth from doing something that was required of them by health professionals.

\section{Mediating the use of and relationships with health services}

An awareness that telecare systems were designed in policy terms to reduce health care service use was evident in patient accounts. The rhetoric of the function of telecare systems had been internalised as a means of preventing or reducing unplanned hospital admissions or general practitioner consultations. 
Contributing to a service which seeks a reduction in use could be seen as acting to offset feelings of blame and lack of entitlement which might have arisen from having a condition seen to be caused by failings in individual responsibility (for example feelings of blame in COPD due to smoking).

Feeling 'less of a nuisance' was a term commonly used by participants and the ability to provide self-monitoring results for health professionals served to both corroborate their own assessment of being unwell (and legitimise service contact) as well as take on work from professionals and thereby reduce their sense of being a burden. Therefore benefiting society and offsetting blame may be more important for some than the perceived utility of telecare in terms of managing or making improvements to a chronic condition.

“...Um, er, I get the impression they no longer see me as trying it on...That maybe just my impression I don't know... I must admit before [pre-telecare] one sometimes got the impression that when, a nuisance you know and you shouldn't be at a doctor's surgery or whatever and I haven't found that at all you know of late [posttelecare]."0.5(ID 16, COPD patient)

Following patients' involvement with telecare, many perceived their relationship with services had changed from one predicated on face-to-face contact with one based largely on 'faceless' contact. Additionally patients were aware of the connection with resource constraint and demand management.

"Well, I, it was described to me as a new initiative to try and keep people out of hospital...Um, because what they found a lot of people with this type of illness... they get emergency admissions to hospital and if you knew what you were doing and you were being monitored on a regular basis, that can be prevented because a trend or a condition, a worsening condition can be recognised earlier and something done about it...And this has worked...There's no doubt about it."0.5(ID 17, COPD patient)

This change in relationship together with the overt aim of cost containment might on the face of things be expected to lead to patients feeling they had a more distanced and isolated relationship with professionals. However, this did not appear to be the case as participants seemingly came to view telecare staff as adequate replacements reversing what was seen as a decline in service contact or content. Service contact was also viewed as having increased without the inconvenience of having to travel.

“Well I don't, I don't see the doctor very much...the nurses ring regularly... but apart from the few days I had in hospital, er, I hadn't seen them for quite a long time, but they do ring regularly, also X, she's at the other end of a computer, she rings regularly, now if she's busy, she passes that over to another girl called X, and she rung this morning...You know, so there's plenty of contact...I mean you've got to recognise that if you, if they say to you, "How are you?" and I say, like I said to you, "I'm in a good spell at the moment,"0.5(ID22, asthma patient)

One of the main benefits people described in the new found relationship with the telecare service provider was being able to speak to the same person each time they used the service. This continuity was important to people and appeared to be something they had not experienced before.

“...yes it's good; it is good because they're a friend but they're a friend that you can just take and put back on the shelf...for the next time you want a friend."0.5(ID 2, diabetic patient)

"Well I talk to $X$ who is at $Y$ [telecare service], who does my alerts, she rings up, oh it's about once every ten days...you know we've got quite friendly now obviously, you know."0.5(ID 12a, COPD patient)
For some participants telecare service operatives were central to the service and were in effect its human element. They were the first port of call in an emergency or even when patients started to feel unwell. Telecare systems could provide instant access to assistance and reassurance without the worry for users that they could be viewed as 'a nuisance' - a feeling that they had experienced when seeking advice from more traditional health services. Indeed the objective measurements of their condition produced by telecare monitoring acted to corroborate their requests for such assistance.

Pre-telecare - ID 19, COPD patient

"I was always ringing the doctors. I got told off by one of them; they phoned me up and said, "Mrs. X you must stop phoning the night doctors," he said, "because you're becoming a nuisance." And they came here and he said to me um; I said to them about my breathing and he said to me, "You haven't got a breathing problem."

Post-telecare - ID 19, COPD patient

“Oh yes, because you feel there's someone there for you. It's awful when you're on your own and you're thinking, "Who can I call, who can I get?" And you know, I can't phone the doctor because that doctor told me off so, you know, it was awful and made it worse and it made me more agitated and the more you got like that the worse the breathing. Now, you see, I'm much calmer and I know I've got that there [telecare device]..."

The technology itself in the case of the asthma consultation service increased access to services. Booking appointments via the Internet was described as providing patients with more choice in terms of timing and selecting which general practitioner with which to consult. The ability to contact general practitioners via email enabled participants to make decisions about their selfmanagement and the need for face-to-face consultations. This combined with their ability to view their medical records appeared to give them a sense of power in accessing and consulting services.

"you can see them one-to-one it is, in that respect, a great service. You can get the appointment usually on the day you want it, but then this is in addition, so it's not that you're, you're not losing anything. It's not replacing, if you don't want to use the online service, you go and see the doctor or the nurse or whoever you want to see, but it's an added thing so it's, in addition I think".0.5 (ID 24, asthma patient)

"it [seeing your records] arms you with ammunition when you go in, you can go in and you can challenge because you can say, this was said, duh, duh, duh, on this date as they go on the computet, you know, they really have, they've got no comeback, you know, from it, "cos you are just quoting what has been said." 0.5 (ID22, asthma patient)

Participants involved in the 'vital' signs monitoring telecare services were usually considerably disabled by their condition and many participants relied on a carer (usually their spouse). The carer would often assist with using the telecare equipment and had to be at least if not more knowledgeable about the telecare than the patient. In the interviews with carers and in those where the carer/ spouse was present, the illness work needed to manage the condition was viewed in terms of a 'team' effort. However, it was often the carer who made the decision to contact health care services and prior to telecare this appeared to have been a fraught decision. As with the patients the telecare service had given them a direct point of access and an objective measurement for legitimizing their contact with health services.

"And have to make the decisions you know...'cos you've always got that, you've always have that thing at the start, before we had the machine, well do we call the doctor or don't we call the doctor? ...Where, and um, you know, you think well by the time you've 
called somebody out, and then perhaps he's got over the crisis... and then you feel like you know, a smaller I don't know what, for calling them out for nothing... and then if you don't call them out and then he gets worse, and then they turn round and say, "Why on earth didn't you call earlier?"0.5(ID 15, spouse of COPD patient) "Can I just say that I feel confident and if something was wrong and $Y$ [telecare user] couldn't, I would immediately go to X [telecare operator]."0.5(ID 4d, spouse of diabetic patient)

Patients and their carers appeared to be re-assured by the telecare systems even though in some cases readings were not analysed for one to two days. Thus access to relationality combined with legitimization of the presence of illness deserving of external attention seems to be more important than the physical health benefits that might flow from improved condition monitoring. A further benefit appeared to be the gaining of a similar level of attention in your own home without the need to travel to health services.

"It would take me at least an hour and a half to two hours travel from here to hospital...so for me, ten minutes...I think I'm getting the same service to a point...because obviously I've got, little bit's are going for me blood test to the doctors......but it's not like an hour and then go ten minutes here and there...probably nothing."0.5(ID 7, diabetic patient)

\section{Discussion}

Policy designed to support the introduction and use of telecare for long term conditions has been based on the gains that are assumed to flow from empowering patients to be self reliant, responsible and activated (Rogers et al., 2009). This is a characteristic of health policy in the UK but also in the US, Australia and elsewhere. In this paper we considered the social practices and processes of the work of telecare integration and incorporation for patients living with a long term condition. The findings of this study suggest a number of benefits for patients of engaging with telecare. In some key respects these were paradoxical and contrary to a fit with policy vision of how telecare is considered to empower patients.

Whilst the new work was highly valued the accommodation of these technologies had different subjective benefits than those of greater patient independence and decreased reliance on the use of services identified by policy makers. Individuals willingly engaged in a narrow set of prescriptions embracing health professional orders whereby the interpretation of signs and symptoms derived from monitoring bypassed the patient and were swiftly traversed over to a clinical gaze for scrutiny. When offered, telecare established users willingly engaged because their main motivations lay in establishing access to timely professional support services rather than becoming 'activated patients'. Thus, telecare services provided not only an adequate substitution for traditional services but provided additional benefits such as minimising the need to travel and the added reassurance of regular external surveillance. Both the frequency of monitoring and the increase in professional control over monitoring meant that telecare led to patients feeling that their condition was being more closely monitored by health services (even in the absence of evidence that this was in fact the case).

Thus, the absence of a shift to meaningful interpretive or managerial work on the part of the participants meant that telecare devices made a negligible contribution to patient initiated self-care (new work being relatively low level (i.e. the monitoring and transmitting of readings)). It may have in fact acted to reinforce a demarcation between professional and patient work whilst increasing access to services. Users of telecare were not necessarily eager to take on more of what was considered professional work and were happy for professionals to retain control over the management of their condition. If anything established users used the equipment to reinforce a traditional divide and embrace the perceived additional professional attention they obtained which was seen to permit accelerated and increased access. At the same time patients felt they were acting as responsible citizens in cooperating with a service deemed to save money for the NHS. Thus, whilst telecare did not encourage patient self activation it served to reduce feelings of unworthiness and burden and brought with it and a new means of accessing relationality with health workers in a context where traditional relationships to services were viewed as diminished or under threat.

In policy terms the failure of telecare to engender a new role for patients in extending the remit of their health work to enable more self-activation and autonomy points to the paradoxical outcome of a reinforcement of moral worth derived from dependency together with a perceived enhanced right to use services. Demand for traditional inpatient services may well reduce but this might be at the expense of increased involvement from new community staff and primary care resources. The latter may result in part from a failure to consider the way in which professional dominance and tasks need to change or be re-distributed. Whilst ever professionals retain the legitimate means and access to the resources for managing chronic illness (e.g. through exclusive rights to diagnose and prescribe) patients actions in using telecare equipment are likely to conform to these pre-set boundaries.

Finally our paper shows how knowledge about the way in which people adapt to telecare for chronic illness in their everyday lives can provide feedback which could be used to modify official policy. It points for example to the need to re-consider the value that telecare is deemed to have for patients, expectations of the outcomes of telecare about the distribution of resources between patients and professionals and the unintended consequences that arise when telecare systems are taken up. Whilst policy makers may not be primarily interested in the lived experiences or practices of patients when they are following the intention of fashioning more responsive services, promoting better self-management or managing demand it is central to re-thinking or adjusting policies to achieving intended policy goals.

\section{Acknowledgements}

The research forms part of a programme of work "Integrating telecare in chronic illness" funded by the Department of Health's Policy Research Programme Research (Grant Reference NIHR ICT 2a 020/0050). We are very grateful to all the participants who made the research possible, and to Dr Cath Exley for her contribution to discussions about the patient telecare work package.

\section{References}

Barlow, J., Bayer, S., \& Curry, R. (2006). Implementing complex innovations in fluid multistakeholder environments: experiences of 'telecare' Technovation, 26(3), 396-406.

Corbin, J., \& Strauss, A. (1988). Unending work and care: Managing chronic illness at home. London: Jossey-Bass.

Denscombe, M. (1998). The good research guide: For small-scale social research projects. Maidenhead: The Open University Press.

Department of Health. (2005). Building telecare in England Scottish Executive.

Department of Health. (2010). Patients' Prospectus - 'Your health, your way - a guide to long term conditions and self care. Department of Health.

Flick, U. (1998). An introduction to qualitative research (1st ed.). London: Sage Publications Ltd.

Gately, C., Rogers, A., Kirk, S., \& McNally, R. (2008). Integration of devices into longterm condition management: a synthesis of qualitative studies. Chronic Illness, $4,135-148$.

Gately, C., Rogers, A., \& Sanders, C. (2007). Re-thinking the relationship between long-term condition self-management education and the utilisation of health services. Social Science \& Medicine, 65, 934-945.

Hudson, J. (2002). Digitising the structures of government: the UK's information age government agenda. Policy and Politics, 30, 515-531. 
Jaana, M., Pare, G., \& Sicotte, C. (2009). Home telemonitoring for respiratory conditions: a systematic review. Am J Manag Care, 15, 313-320.

Lehoux, P., Saint-Arnaud, J., \& Richard, L. (2004). The use of technology at home: what patient manuals say and sell vs. what patients face and fear. Sociology of Health \& Illness, 26(5), 617-644.

Maric, B., Kaan, A., Ignaszewski, A., \& Lear, S. A. (2009). A systematic review of telemonitoring technologies in heart failure. European Journal of Heart Failure, 11, 506-517.

May, C., Finch, T., Cornford, J., Exley, C., Gately, C., Kirk, S., et al. (2010). Integrating telecare for chronic disease management in the community: What needs to be done? (Rep. No. 020/0050) NIHR ICT.

May, C., Finch, T., Mair, F., \& Mort, M. (2005). Towards a wireless patient: chronic illness, scarce care and technological innovation in the United Kingdom. Social Science \& Medicine, 61, 1485-1494.

May, C., Mair, F., Finch, T., MacFarlane, A., Dowrick, C., Treweek, S., et al. (2009). Development of a theory of implementation and integration: normalization process theory. Implementation Science, 4, 29.
Nicolini, D. (2007). Stretching out and expanding work practices in time and space: the case of telemedicine. Human Relations, 60, 889-920.

Obstfelder, A., Engeseth, K., \& Wynn, R. (2007). Characteristics of successfully implemented telemedical applications. Implementation Science, 2, 25.

Oudshoorn, N. (2008). Diagnosis at a distance: the invisible work of patients and healthcare professionals in cardiac telemonitoring technology. Sociology of Health E Illness, 30, 272-288.

Rogers, A., Bury, M., \& Kennedy, A. (2009). Rationality, rhetoric, and religiosity in health care: the case of England's expert patients programme. International Journal of Health Services, 39, 725-747.

Stamm, T., Lovelock, L., Stew, G., Nell, V., Smolen, J., Jonsson, H., et al. (2008). I have mastered the challenge of living with a chronic disease: life stories of people with rheumatoid arthritis. Qualitative Health Research, 18, 658-669.

Verhoeven, F., van Gemert-Pijnen, L., Dijkstra, K., Nijland, N., Seydel, E., \& Steehouder, M. I. (2007). The contribution of teleconsultation and videoconferencing to diabetes care: a systematic literature review. Journal of Medical Internet Research, 9, e37. 